\section{Enhancing Scholarly Publications: Developing Hybrid Monographs in the Humanities and Social Sciences}

\author{
Nicholas W. Jankowski, Andrea Scharnhorst, \& Clifford Tatum \\ Royal Netherlands Academy of Arts and Sciences
}

Zuotian Tatum

Leiden University Medical Center
Scholarly and Research

Communication

VOLUME 4 / ISSUE $1 / 2013$
Nicholas W. Jankowski is Associate Researcher at the eHumanities Group, Royal Netherlands Academy of Arts and Sciences (KNAW). $\mathrm{He}$ is editor of e-Research: Transformation of Scholarly Practice (Routledge, 2010). Email:nickjan@xs4all.nl.

Andrea Scharnhorst is head of e-Research at Data Archiving and Networked Services (DANS), and Scientific Coordinator, eHumanities Group, Royal Netherlands Academy of Arts and Sciences (KNAW). Anna van Saksenlaan 10, 2593 HT The Hague, The Netherlands. Email: andrea. scharnhorst@dans.knaw.nl .

Clifford Tatum is $\mathrm{PhD}$ candidate at Leiden University, project manager of Academic Careers Understood through Measurement and Norms (ACUMEN), and Associate Researcher at the KNAW e-Humanities Group. Web: tatum.cc; Email: clifford@ tatum.cc .

Zuotian Tatum is Scientific Programmer for the Human Genetics Group at Leiden University Medical Center. She is also a freelance software developer, working with WordPress for academic scholarship on the Web. Email: z.tatum@ lumc.nl.

\begin{abstract}
(C) 2012 Nicholas W. Jankowski, Andrea Scharnhorst, Clifford Tatum, \& Zuotian Tatum. This Open Access article is distributed under the terms of the Creative Commons Attribution Non-Commercial License (http://creativecommons.org/licenses/by-nc-nd/2.5/ca), which permits unrestricted noncommercial use, distribution, and reproduction in any medium, provided the original work is properly cited. Scholarly Publications: Developing Hybrid Monographs in the Humanities and Social Sciences. Scholarly and Research Communication, 4(1): 010138, 26 pp.

Journal URL: www.src-online.ca

Received January 9, 2012, Accepted June 18 2012, Published December 19, 2012

Abstract
\end{abstract}


Scholarly and Research

\section{Communication}

VOLUME 4 / ISSUE 1 / 2013

\section{Introduction}

Scholars in the humanities and social sciences are increasingly considering possibilities for making research available on the Web. ${ }^{1}$ Instruments for data collection and analysis, datasets and metadata describing this material, conference papers, and project reports are appearing (and in some cases are required to be placed) in Web-based repositories. ${ }^{2}$ One area receiving less attention in this trend, however, is the development of Web venues that integrate the traditionally published book with the diverse materials related to an overall research project. "Enhanced publication" is a term reflecting such integration, and a range of initiatives have been supported by the SURFfoundation in the Netherlands to develop such forms of publication. ${ }^{3}$ SURF is a publicly founded organization, responsible for administrative coordination and for initiating information and communication technology (ICT) driven innovation in the area of higher education and research. SURF regularly issues tenders for innovative projects, including for the preparation of enhanced publications.

The project "Enhancing Scholarly Publishing in the Humanities and Social Sciences" was one of six projects of the last tender call for SURF. This report, written by the researchers conducting this project, elaborates on the main intentions and accomplishments during that period. ${ }^{4}$ Initiated in January 2011, Enhancing Scholarly Publishing was designed to prepare websites for four scholarly books which had previously been traditionally-published and, in the process, to utilize a model of and tools for enhanced publications developed by SURF. By way of conclusion, we reflect on some of the challenges encountered, and sketch paths meriting further exploration, when developing enhanced publications.

This report begins with a backdrop of more general initiatives for enhancing print publications and proposes a definition of the term "enhanced publication" as relevant to this project. That panorama and definition are followed by the presentation of the objectives of the Enhancing Scholarly Publishing project and the conceptual principles underlying the database architecture for the book websites. Three of the four websites are presented in the next section (the fourth book that was part of the project is in production and insufficiently developed for inclusion in this report). Finally, in the conclusion section we reflect on the overall project and note areas where further research and development should be undertaken.

\section{Enhancing publications \\ PANORAMIC OVERVIEW}

The enhancement of print publications has been an ongoing endeavour, at least since Gutenberg, if not earlier (Palmer \& Frangenberg, 2000). Manuscripts artistically and elaborately illustrated by monks in monasteries suggest interest in enhancement as far back as the Middle Ages. More contemporary practices of including visualizations in books - tables, figures, photographic plates - are extensions of such enhancement. In the current Digital Age, many publishers are exploring ways to integrate printed text with dynamic visualizations and supplementary digital materials available on the Internet, both within and outside of academia. ${ }^{5}$ This project was designed around Web technologies for conventional personal computers. However, present developments of enhanced publications are making use of mobile devices and e-tablets. Scholarly

Nicholas W. Jankowski, Andrea Scharnhorst, Clifford Tatum, \& Zuotian Tatum. (2012). Enhancing Scholarly Publications: Developing Hybrid Monographs in the Humanities and Social Sciences.

Scholarly and Research Communication, 4(1): 010138, 26 pp. 
presentations are also being developed for the iPad platform, including a version of The Iliad containing both the original Greek and English translations, ${ }^{6}$ Jack Kerouac's novel On the Road, including a wide range of supplementary materials ${ }^{7}$ (e.g., maps of the journey, audio files, original manuscript), and T. S. Elliot's seminal poem The Waste Land, showing some pages of the original manuscript, audio readings synchronized to the text, annotations explaining passages, and interpretations by Elliot scholars on the poem. ${ }^{8}$ Popular science publications, perhaps less scholarly in objective but nevertheless engagingly interactive, include a range of entries prepared by Touch Press in association with Faber and Faber. Solar System for iPad (Chown, 2011) is the widely acknowledged "crown jewel" in the growing series of titles being prepared by these two collaborating publishers. ${ }^{9}$

A scholarly initiative in enhancement is the decade-long research enterprise for the project entitled Visualizing Culture - Image-Driven Scholarship. This enterprise was initiated at the Massachusetts Institute of Technology (MIT) and involves the compilation of images and texts related to historical studies of Japan and China, all available in a Web environment. ${ }^{10}$ Designed for both research and educational objectives, the images are housed in a database, and more than a hundred videos are included on the site (see Figure 1).

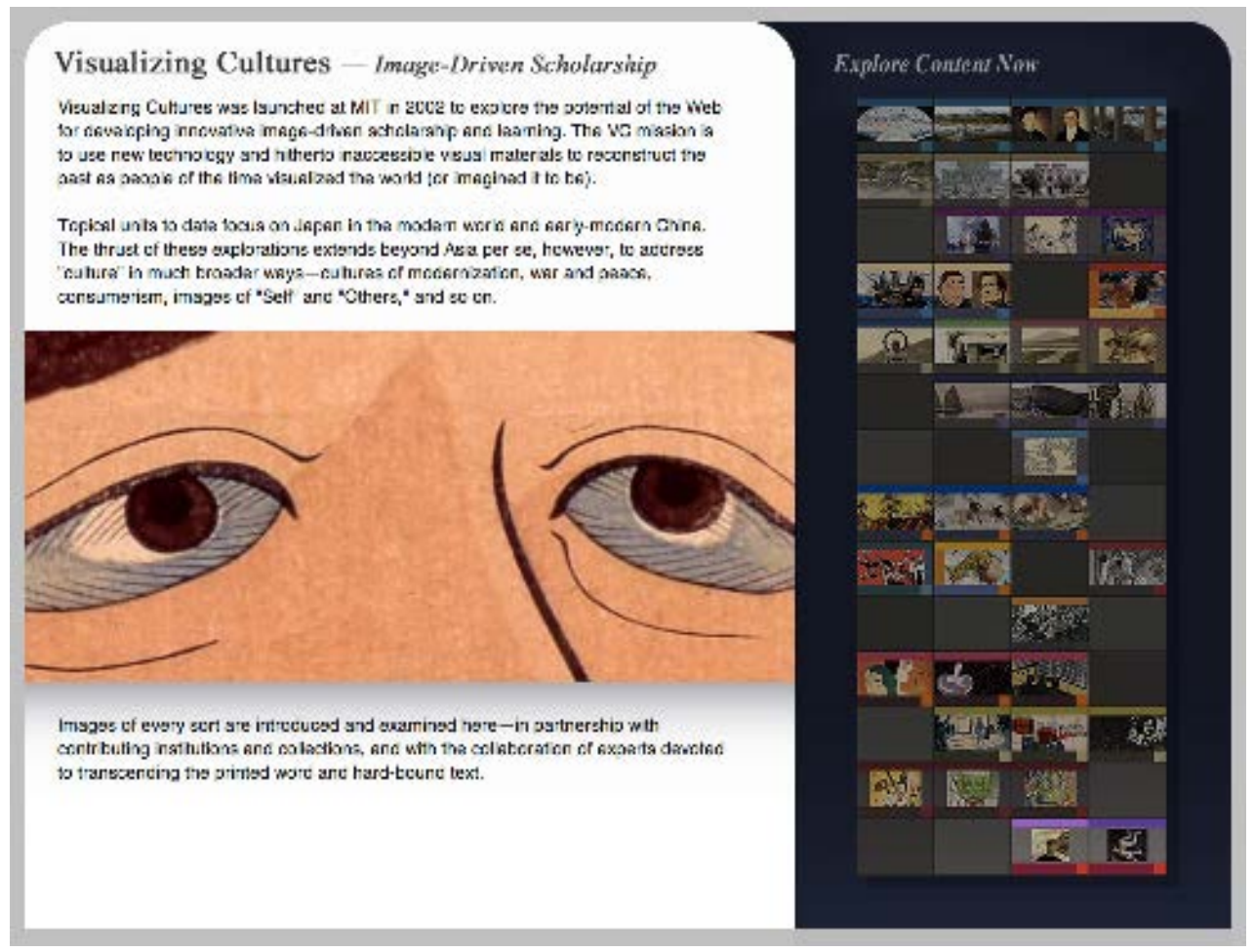

Figure 1: Screenshot from Visualizing Cultures. Source: http://ocw.mit.edu/ ans7870/21f/21f.027/home/index.html

One of the most far-reaching scholarly publications integrating scholarly data with its publication is the Mark Twain Project (http://www.marktwainproject.org/). As expressed in its mission statement, the "ultimate purpose is to produce a digital critical edition, fully annotated, of everything Mark Twain wrote" (Mark Twain Project, 2012, para. 2). The project reflects long-term collaboration between the University of 
Scholarly and Research

\section{Communication}

VOLUME 4 / ISSUE 1 / 2013
California Bancroft Library and the University of California Press, resulting in both traditionally printed volumes as well as Web access to digital versions of the volumes and the original sources on which the publications are based.

In comparison to the above-mentioned projects, initiatives from most academic book publishers fall short when it comes to enhancement. The situation is different in the area of journal publications. Here, traditional academic publishers are rapidly providing a host of features for the traditionally staid and text-dominated journal article. Elsevier, through its subsidiary Cell Press, prepared a far-reaching initiative called the Article of the Future, launched in July 2009. ${ }^{11}$ A year later it had been implemented in the score of Cell Press journal titles. Figure 2 shows several of the features available for articles in the journal Cell: pop-up illustrations and in-text references, a navigation bar to sections of the article, and dynamic updating of reference citations.

\section{Graphical abstract PaperFlick}

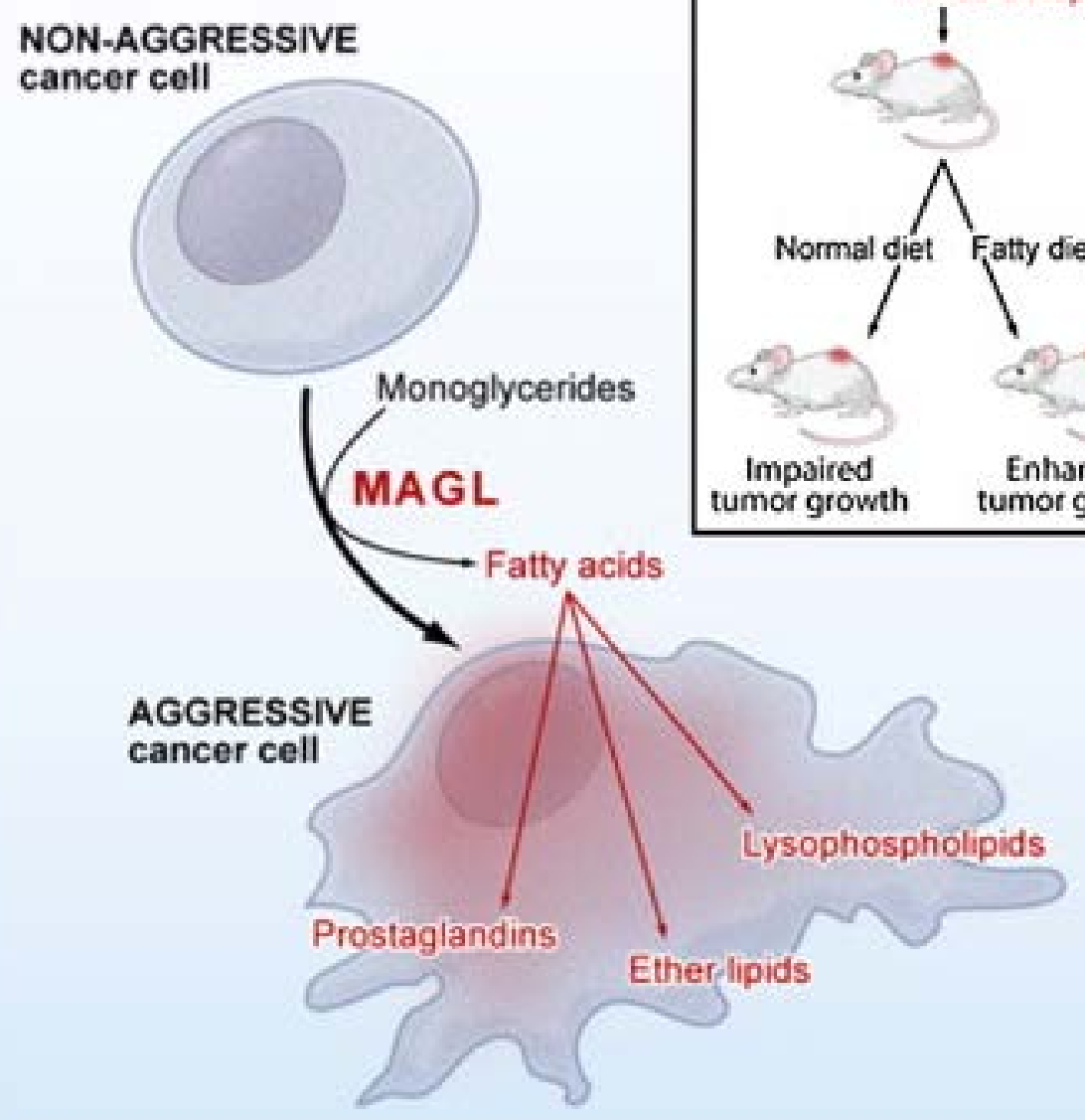

Figure 2: Screen Shot of Pop-up visualization, Elsevier "Article of the Future." Source:http://cell.com/ 
Many of the Web features found in the Cell Press journal articles are also suitable for inclusion in websites accompanying traditionally published book monographs. However, few of these features are commonly found on the websites prepared to accompany printed scholarly books in the humanities and social sciences. In that regard, this project represents a step forward in preparation of enhanced publications within the humanities and social sciences.

\section{WHAT IS AN ENHANCED PUBLICATION?}

An increasing body of literature is appearing that elaborates on the idea of an "enhanced publication" (e.g., Boulal, Lordanidis, Quast, \& Schirrwagen, 2010; Hoogerwerf, Jong, $\&$ Scholte, 2009). One of the more extensive reviews of this literature (WoutersenWindhouwer \& Brandsma, 2009) proposes the following definition:

[An enhanced publication is] a publication that is enhanced with research data, extra materials, post publication data, database records (e.g. the Protein Data Bank), and that has an object-based structure with explicit links between the objects. In this definition an object can be (part of) an article, a data set, an image, a movie, a comment, a module, or a link to information in a database. (WoutersenWindhouwer \& Brandsma, 2009, p. 20)

Since formulation of this definition, debate around what constitutes an enhanced publication continues. Most recently, Breure, Voorbij, and Hoogerwerf (2011) proposed a new term, "Rich Internet Publication," which they suggest can be seen as a scale that reflects degrees of involving integration, visualization, and exploration.

Aware of the need for further exploration of types of enhancement suitable for scholarly publications, SURF issued a round of funding for pilot projects in 2010. In the call for proposals, to which the Enhancing Scholarly Publications project was submitted, the term "enhanced publication" is described as follows:

An Enhanced Publication consists of a publication, usually in the form of text, enhanced with extra material. A publication can be an article in a journal, a dissertation, report, memo, or a chapter in a book. The condition is that it is related to (scientific) research and includes an interpretation or analysis of the primary data or derivative thereof. The supplementary material can, for example, consist of research data, illustrative images, meta datasets, and post-publication data, such as comments and ranking data. Given the changes in post-publication data, it is possible that an Enhanced Publication continues to develop across time. (Author translation of text, "Wat is een Verrijkte Publicatie?" SURFfoundation, 2010)

Enhancement of publications involves a range of concrete tasks, and WoutersenWindhouwer and Brandsma (2009, pp. 54-55) propose a checklist for preparation of the objects included in an enhanced publication:
VOLUME 4 / ISSUE $1 / 2013$ 
Scholarly and Research

VOLUME 4 / ISSUE 1 / 2013
- Providing persistent identifiers that are unique and global;

- Ascertaining timestamp and citation information;

- Using of file types commonly available;

- Ensuring that datasets have universal numeric identification;

- Achieving adequate technical quality to merit preservation;

- Considering legal issues related to incorporation of materials.

They also suggest various forms of additional information related to objects in enhanced publications: availability and sustainability; ownership and responsibility; and indication whether an object has been peer reviewed, ranked, cited, and commented upon. The linking of objects within an enhanced publication merits consideration in a meaningful manner, they suggest, balancing complexity with utility. Moreover, the relation between linked objects (e.g., a chapter being part of a book) should be made clear. The above definition stresses permanence, persistence, and authenticity — an approach understandable from the perspective of the institutions involved in preserving text, i.e., repositories for scientific publications and research libraries. ${ }^{12}$

But persistence and permanence are only two aspects of an enhanced publication; linking information in an interoperable and machine-readable manner to be processed over the Web is another facet. Various standards, protocols, and tools have been developed to facilitate preparation of enhanced publications. Perhaps the most important of these are the Resource Description Framework (RDF) and especially the Open Archives Initiative Object Reuse and Exchange (OAI-ORE), the latter of which "develops and promotes interoperability standards that aim to facilitate the efficient dissemination of content" (Woutersen-Windhouwer \& Brandsma, 2009, p. 51). Figure 3 below depicts typical object relationships in the form of subject-predicate-object statements (triples). OAI-ORE handles the aggregation of RDF triples that describe the relations between the publication, its sub-components (such as chapters, illustrations, and references), and related Web resources. Without elaborating here on specific relations, the figure illustrates the logic of RDF triples, which are the foundation of semantic interoperability. ${ }^{13}$

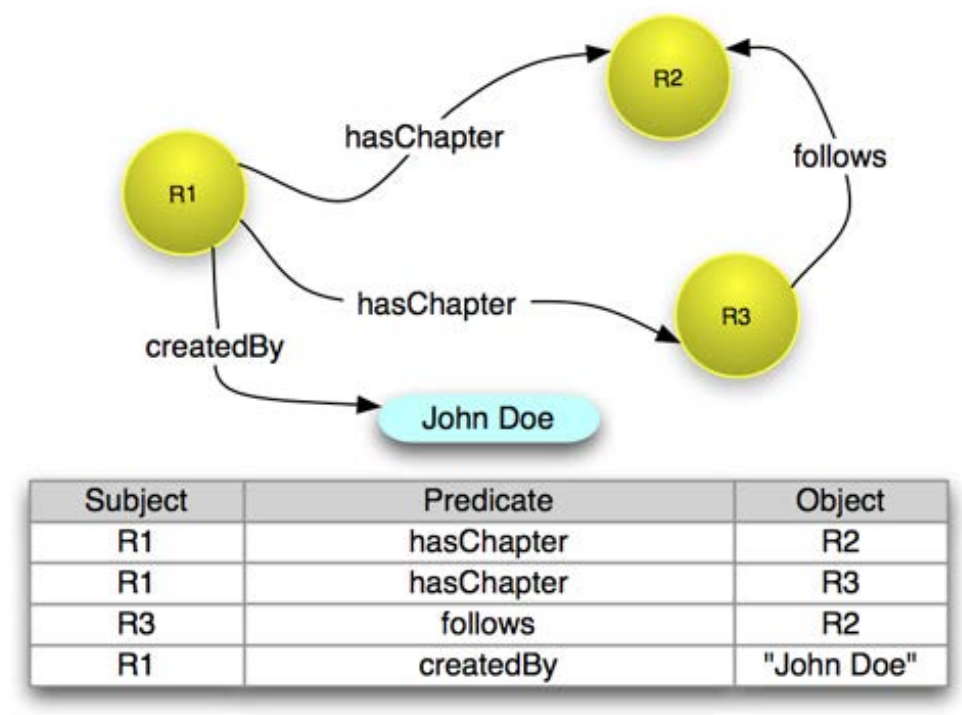

Figure 3: Basic RDF Structure. Source: http://www.openarchives.org/ore/1.o/primer\#rdf 
Data models such as the Resource Description Framework (RDF) (as shown in Figure 3) belong to technical specifications developed by the World Wide Web Consortium $\left(\mathrm{W}_{3} \mathrm{C}\right)$, and are part of Semantic Web technologies. Originally designed as a data model for metadata, RDF was applied to bibliographic references, for example. This immediately points to one of the challenges confronting this project. Despite the long tradition of bibliographic referencing, interoperability among reference managers and beneath the layer of ontologies is far from perfect. A variety of classification schemes and ontologies exist that are used for bibliographies. Although traditional bibliographic entries usually indicate the author(s), title of document, publisher, year of publication, and specification of details when the document is an article in a periodical, the elements included in the ontology or categorization can change between different bibliographic systems. Common problem areas include references to special issues and serials, and disambiguation of contributor roles, such as editors and authors. But the aim of enhanced publications goes far beyond the creation of an automatic construction of bibliographic data.

The OAI-ORE model depicted in Figure 4 below contains elements such as:

- seeing a scholarly work as an aggregation of different contributions

- flagging out sources for discursive arguments in the text

- highlighting the different roles among contributors, such as authors, editors, and sometimes objects of research

- linking to other related material (from research data, to visualizations, to other related work)

In the description of this project we present specific solutions to some of those problems.

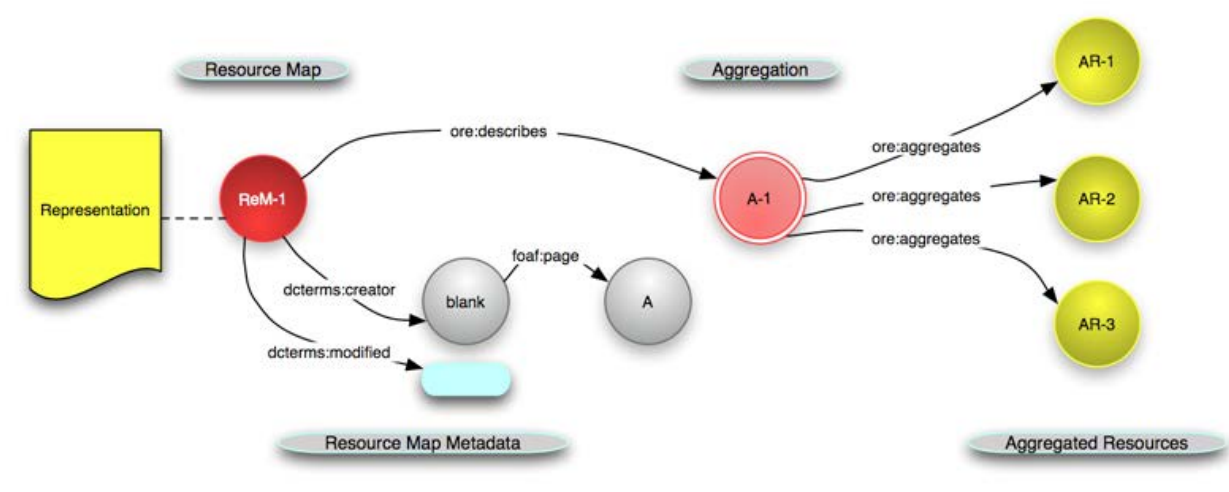

Figure 4: OAI-ORE Aggregation. Source: http://www.openarchives.org/ore/1.o/ primer\#rdf

\section{Project objectives, platform design, and website features Project Design}

Two central objectives were formulated for the SURF project Enhancing Scholarly Publishing: (1) to develop hybrid forms of publications, and (2) to develop a database 
Scholarly and Research

\section{Communication}

VOLUME 4 / ISSUE 1 / 2013 allowing for aggregation of content attributes and associations across the individual book websites (Jankowski, 2011).

Regarding the first objective, a template constructed within the WordPress platform was to be used to construct websites to complement the four selected books. These websites were to contain a broad range of features:

- Supplementary resources (e.g., links, blogs, chapter appendices, author profiles);

- Chapter visualizations (e.g., animations, figures, tables) in colour;

- Hyperlinks, both internal and external, to the book texts;

- Author updating of site materials;

- Search features.

Regarding the second objective, a database was to be developed that would allow for aggregation of content attributes and associations across the individual book websites, such that topical relationships, intellectual underpinnings, and contextual factors could be made explicit. Fundamental to this approach is a focus on Web-based texts as dynamic and evolving discourses rather than completed works ready to be archived.

In this project, the WordPress (http://wordpress.org/) Content Management System (CMS) was employed as the foundation for the websites, both for its relative ubiquity and ease of use. An additional motivation was the widespread use of this platform. According to the recent World Wide Web Technology Survey, ${ }^{14}$ roughly $30 \%$ of the 1 million largest websites on the Internet use a CMS. Of the websites using a CMS, WordPress holds 54\% market share.

Four books were selected as pilots to be included in the project: three edited anthologies and a single-author university-level textbook:

- Jankowski, N. W. (2009). e-Research: Transformation in Scholarly Practice. New York, NY: Routledge.

- Wouters, P., Beaulieu, A., Scharnhorst, A., \& Wyatt, S. (2012). Virtual Knowledge: Experimenting in the Humanities and Social Sciences. Cambridge, MA: MIT Press. [2013].

- Park, D., Jankowski, N. W., \& Jones, S. (2011). The Long History of New Media: Technology, Historiography, and Newness Contextualized. New York, NY: Peter Lang.

- Jankowski, N. W. (forthcoming). Digital Media: Concepts \& Issues, Research, \& Resources. Cambridge, UK: Polity Press. [2013].

All books belong to the area of communication sciences, media studies, and science and technology studies. 
As reflected in Figure 5, a conceptual diagram of the project representing the content of each book website is managed with a local database, connected to a central database. In this way, the linkage is established for aggregation and each book website retains an individual Web presence with local content management and storage.

The following websites have been developed as part of this project:

- Central Project website: http://ep-books.ehumanities.nl

- e-Research book website: http://scholarly-transformations. virtualknowledgestudio.nl

- Long History of New Media book website: http://thelonghistoryofnewmedia.net

In addition to these websites, a central accomplishment for the project is the launch of Semantic WordPress for Digital Scholarship, termed Semantic WORDS, ${ }^{15}$ which is comprised of two specially tailored open source plugins designed to introduce traditionally published books to Web-based scholarly communication.

Each of the websites contain possibilities for a broad range of features intended to enhance the printed versions of these books, including supplementary resources, visualizations, intertextual linking of content, and formal structuring of content using Semantic Web ontologies. In a subsequent phase, a central database will be established to facilitate aggregation of content across the individual book websites, such that object relationships, discursive threads, and contextual factors can be traced across the collection.

\section{EP Project Concept}

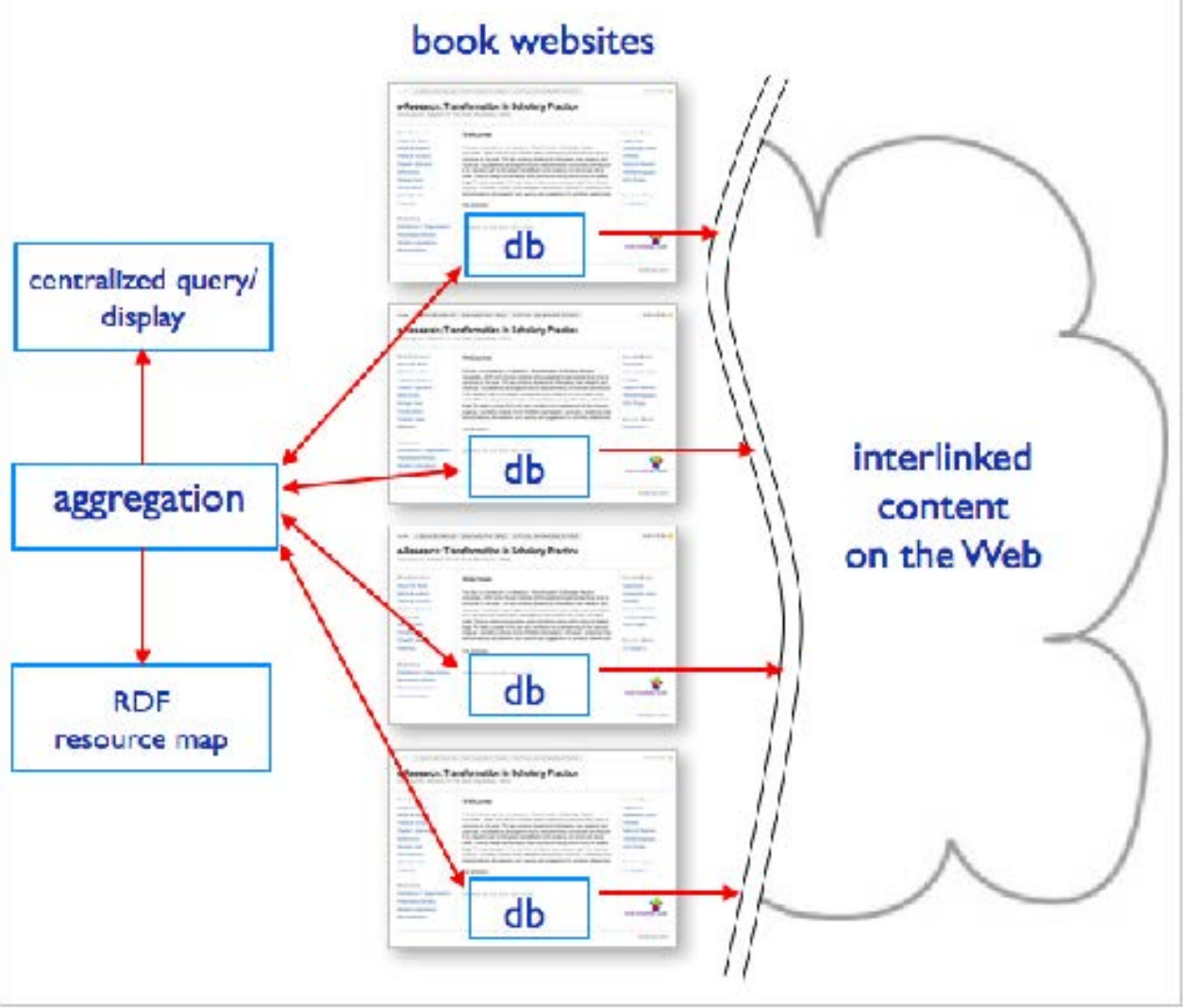

Figure 5: Concept diagram of Enhanced Publication project.

Nicholas W. Jankowski, Andrea Scharnhorst, Clifford Tatum, \& Zuotian Tatum. (2012). Enhancing Scholarly Publications: Developing Hybrid Monographs in the Humanities and Social Sciences. Scholarly and Research Communication, 4(1): 010138, 26 pp. 
Scholarly and Research

\section{Communication}

VOLUME 4 / ISSUE 1 / 2013

\section{TOOL DEVELOPMENT}

The development strategy for this project focused in the first place on academic practice: how academics in the social sciences and humanities conduct scholarship. This priority informed development-specific functionality and interfaces. To this end, the relative ease of using WordPress played an important role. Figure 6 displays the functional modules of the platform in three clusters: the WordPress software (upper left), community-developed WordPress plugins (lower left), and the custom-developed plugins (right).

\section{Semantic WordPress for digital scholarship}

The Semantic WordPress for Digital Scholarship framework (Semantic WORDS: http:// ep-books.ehumanities.nl/semantic-words) is the basis for this hybrid platform, ${ }^{16}$ which leverages Web 2.0 participatory modes of scholarly communication combined with formalized content structures imposed by Semantic Web formats (see Figures 6 and 7).

Semantic Web stands for a new generation of data models and web technologies. The vision proposed by Tim Berners-Lee (2002) aims for a web of data on top of the existing network of web resources linked by hyperlinks. One could also talk of a giant, machine-readable index to the Web. Different to the Web 2.0, in which user-generated content and platforms for information sharing are central, the Semantic Web or Web 3.o stands for standards, new data representations, and models that are machinereadable, and so support automatic knowledge ordering.

The term Web 2.0 is typically used to mark the transition to user-generated content on the Web. From this perspective, content on the Web interconnects with the use of hyperlinks. By adding content and linking to relevant webpages, users facilitate the construction of meaning through associative links. The aggregate of user-generated content gives rise to the search engine as a dominant navigation tool. The Semantic Web is an effort to formalize content structure through the creation of centralized (as opposed to emergent) content ontologies.

For enhanced publications, the Semantic Web approach facilitates increased granularity of web objects and increased precision of the semantic meaning between objects. Increased granularity means the book is comprised of its constituent parts, for example, chapters, images, and references, each of which is uniquely identified.

The role of a content ontology is (1) to define meaningful relationships (instead of simple hyperlinks) between and among objects and (2) to assign precise types to each of the objects. For example, in a Web 2.o environment, the user gives the hyperlink any meaning she chooses, whereas using Semantic Web format "book" and "chapter" have specific, standardized meanings. In Web 2.0, both a book and a chapter are just html objects and a search engine cannot distinguish between them, but in Semantic Web they are distinct types with unique identifiers. 
The Semantic WORDS software was developed as open source for use with the WordPress Content Management Software, which is also open source. Semantic WORDS is comprised of two custom plugins that are integrated with WordPress and Zotero (http://www.zotero.org/), an open source Web annotation and citation management system.
Scholarly and Research

VOLUME 4 / ISSUE 1 / 2013

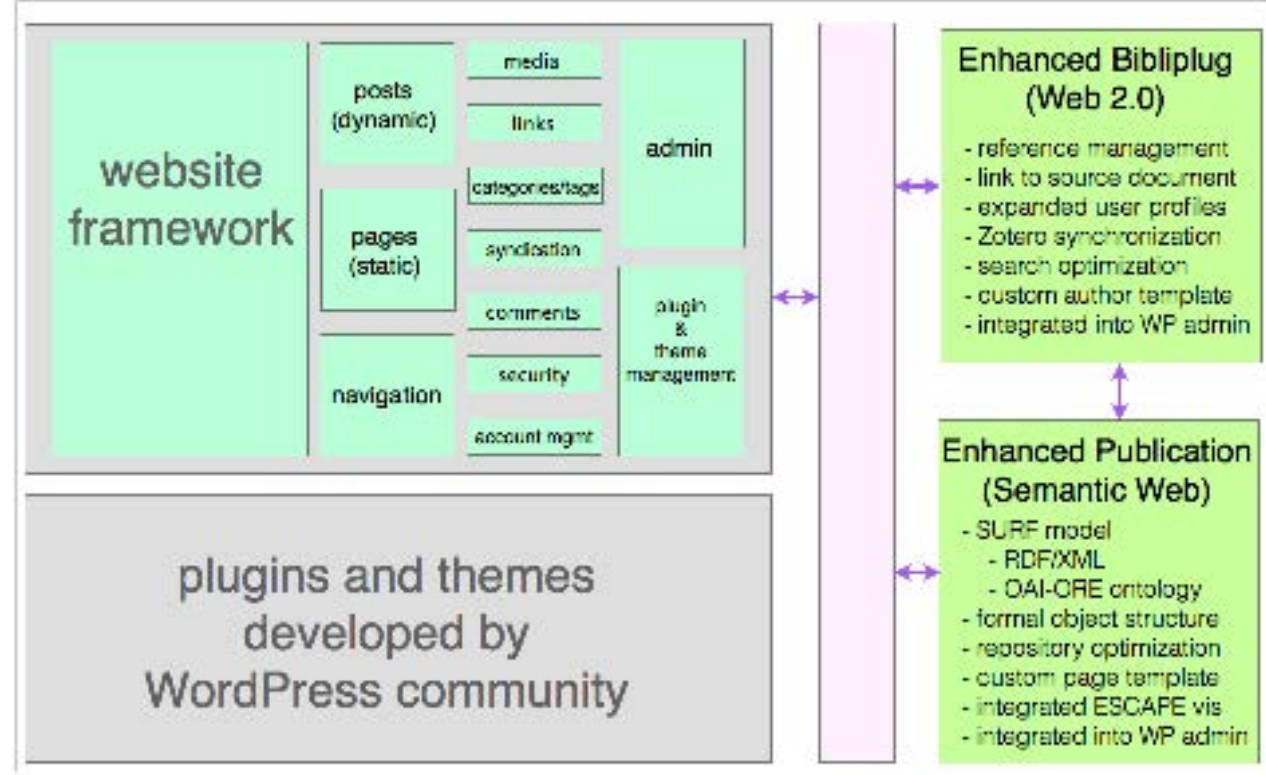

Figure 6: Semantic WORDS functional diagram.

\section{Enhanced Bibliplug}

The first of the Semantic WORDS plugins, Enhanced Bibliplug, (http://ep-books .ehumanities.nl/semantic-words/enhanced-bibliplug), provides a suite of features for authors, which are focused on organization and publication of academic content on the Web. Features include custom page templates for academic texts, integration with Zotero for citation management, and expanded author profile pages for CV content management, such as publications, presentations, projects, and other related career accomplishments. In addition to providing authors with advanced tools for publishing on the Web, Bibliplug facilitates visibility (e.g., in search engines) of relationships between and among researchers, institutions, and both formal and informal scholarly communication.

Bibliplug was first developed for the Virtual Knowledge Studio in 2009 and is still in use on some dozen project-related websites. At the time of its development, the goal was to create a central repository for all researchers affiliated with the Studio to organize their academic work. The initial design included (a) database schema for storing bibliographical references, (b) administration pages to manage the references, and (c) short code for easy retrieval of references based on author, year, and publication type.

In this project, we further developed the plugin and re-released it as Enhanced Bibliplug. Added functionalities include (a) the ability to connect and synchronize with Zotero accounts (see Figure 7), (b) a custom Author page template to display a 
Scholarly and Research

\section{Communication}

VOLUME 4 / ISSUE 1 / 2013 user's academic title and affiliation, biography, and CV content such as publications and presentations, (c) the ability to export bibliography data in RDF format based on Semantic Publishing and Referencing (SPAR) Onotologies, and (d) the ability to group references based on categories and tags.

\section{Enhanced publication for WordPress}

The second plugin, Enhanced Publication for WordPress (http://ep-books.ehumanities .nl/semantic-words/enhanced-publication-plugin-for-wordpress), works in parallel with Bibliplug. Added content is simultaneously structured in Semantic Web formats based on academic publishing ontologies. Unlike many Semantic Web applications, this plugin includes integration of a visualization feature, such that object relationships can be browsed with the InContext application developed by the SURFfoundation. The central function of this plugin is to describe a WordPress site as an OAI-ORE aggregated book (an enhanced publication). In this structure, we convert WordPress pages into book chapters and use various other plugins to facilitate and describe reference lists, authors and editors, and attachments. For visualizing the content object relationships, we employ SURF's InContext Visualiser, which is shown at Figure 8 (http://www.surffoundation.nl/en/projecten/Pages/ EscapeVisualisationcomponent.aspx).

\section{RDF AND ONTOLOgIES: BACKBone OF SEMANTIC WORDS}

As mentioned in the introduction, we aimed to create a Web-based representation of resources, which is also machine-readable. The notion of a Semantic Web was introduced by Tim Berners-Lee (Berners-Lee, Hendler, \& Lassila, 2002) to indicate a move from a Web of resources or documents to a "Web of data." If the Web is compared to a collection of items in a library, the Semantic Web could be compared to the creation of catalogues and indexes to describe the content of the collected items in a meaningful way. To be interoperable, such indexes need to be constructed in a standardized way. Consequently, Semantic Web technologies use "formal (usually symbolic) representation languages where some meaning is encoded separately from data and content" (Meroño-Peñuela, Ashkpour, Van Erp, Mandemakers, Breure, Scharnhorst, Schlobach, \& Van Harmelen, 2012, p. 11). A set of different technologies belong to the Semantic Web approach, among them RDF as a general method to describe information, and ontologies as knowledge representation languages (see Wikipedia, 2012).

This combination of website features and book objects necessitated use of a particular set of ontologies to cover the hybrid configuration of book contents published as a website. In particular, the visualization layer (InContext visualizer) expects roles to be defined in a particular way. We therefore selected a list of related ontologies to describe the full content of the aggregation. Following is a list of ontologies used:

- RDF: Resource Description Framework Ontology;

- OAI-ORE Vocabulary for Resource Aggregation;

- DCTerms: Dublin Core Metadata Ontology;

- FOAF: Friend of a Friend Ontology;

- FRBR: Functional Requirements for Bibliographic Records Ontology; 
- SWAN: Provenance, Authoring, and Versioning in scientific discourse Ontology;

- RES: Academic Researchers Ontology;

- BiRO: Bibliographic Reference Ontology;

- FaBiO: FRBR-aligned Bibliographic Ontology;

- PRISM: Publishing Requirements for Industry Standard Metadata Ontology;

- ESCAPE-Display: Vocabulary for describing inverse relationship of FOAF.

In addition to customized plugins, several other plugins are used from among the wide range of open source plugins developed by the WordPress community (see Figure 9). We use an additional three plugins to augment functionality in our custom plugins: Co-Authors Plus (http://wordpress.org/extend/plugins/co-authors-plus/), Ninja Page Categories and Tags (http://wpninjas.net/plugins/ninja-page-categories-and-tags/), and User Avatar (http://wordpress.org/extend/plugins/user-avatar/). ${ }^{17}$

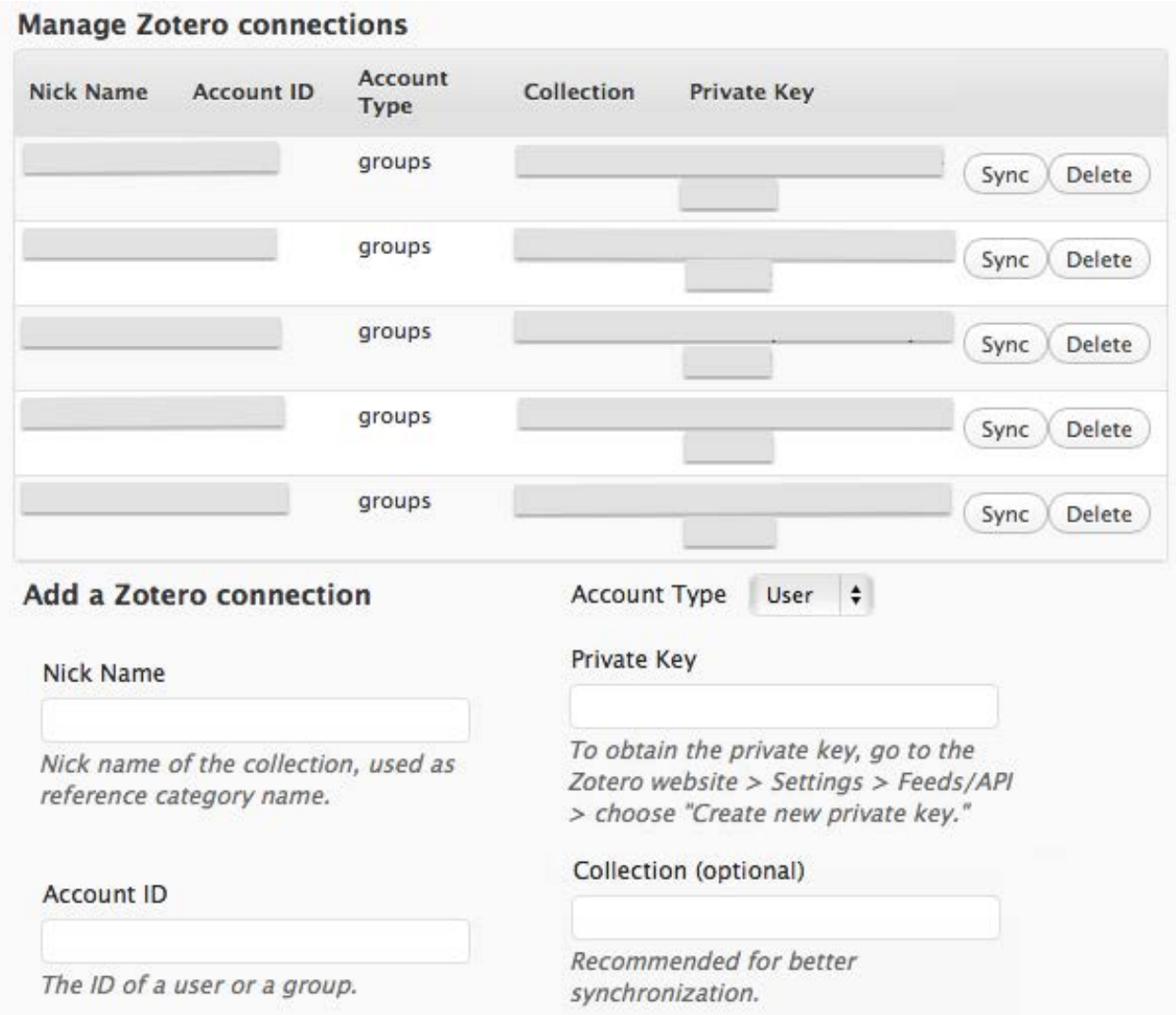

Figure 7: Zotero Connector admin page in WordPress 


\section{Scholarly and Research}

\section{Communication}

VOLUME 4 / ISSUE 1 / 2013

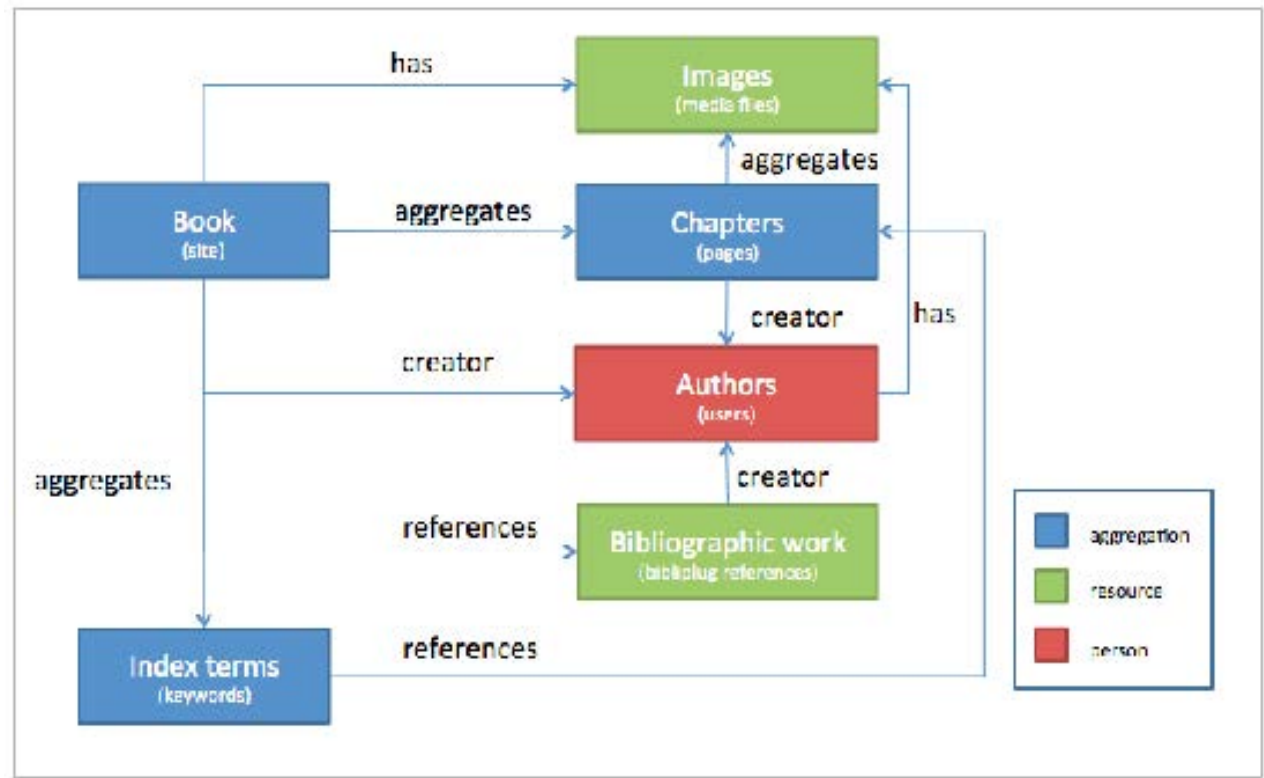

Figure 8: Semantic WORDS aggregation structure

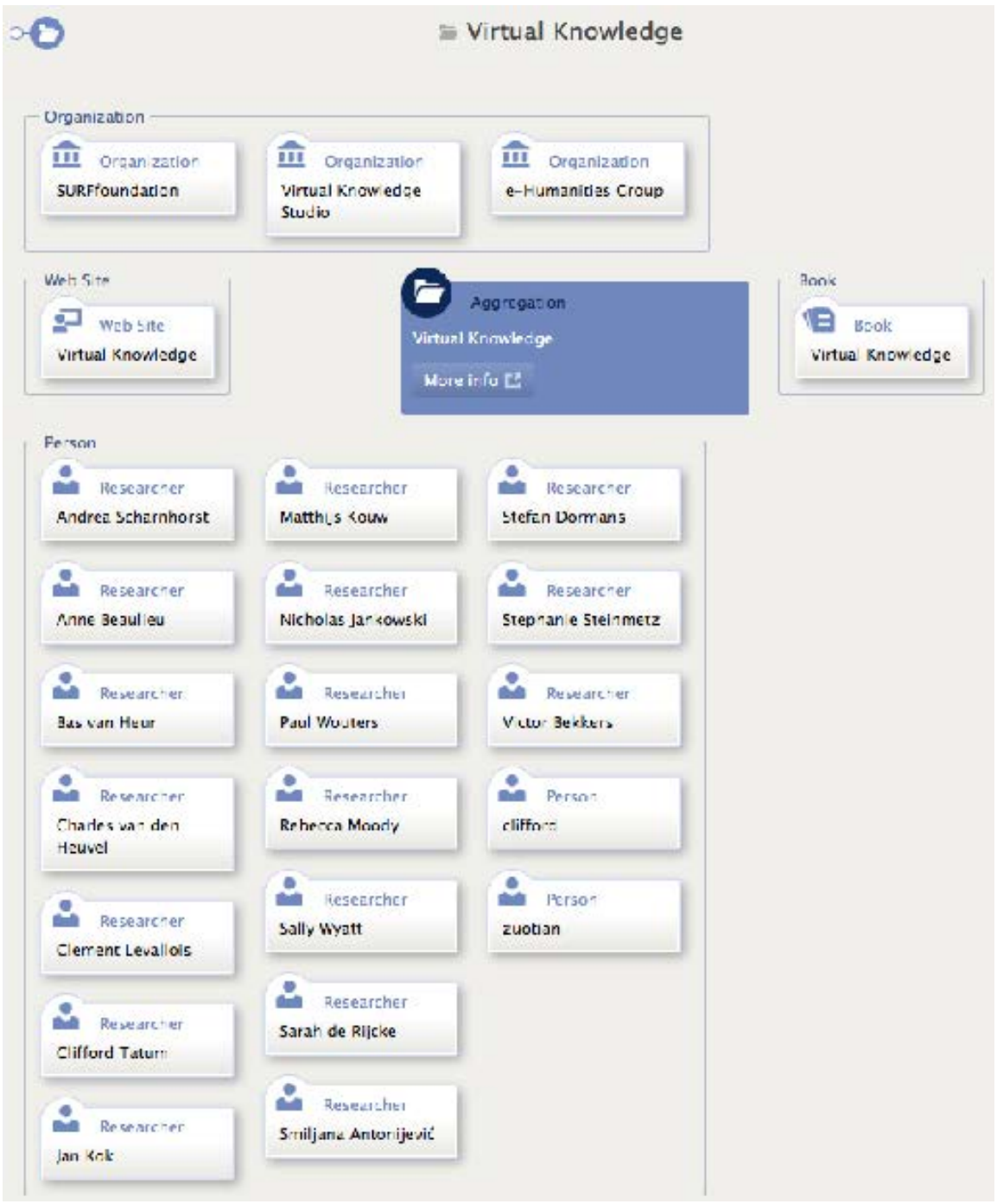

Figure 9: InContext Visualization, Virtual Knowledge website

Nicholas W. Jankowski, Andrea Scharnhorst, Clifford Tatum, \& Zuotian Tatum. (2012). Enhancing Scholarly Publications: Developing Hybrid Monographs in the Humanities and Social Sciences. Scholarly and Research Communication, 4(1): 010138, 26 pp. 


\section{Implementing enhancement}

This section outlines the steps undertaken in developing the Web presence for the three traditionally published books noted above using the Semantic WORDS framework. Inasmuch as there are specific details and features related to each, they are presented separately below. All of the book-related websites, however, are based on a uniform template constructed within the WordPress content management system described in the previous section.

BooK 1: E-RESEARCH

The book e-Research: Transformation in Scholarly Publishing was released in mid2009 by Routledge and reflects the characteristic features of traditionally published and specialized scholarly monographs: hardcover, black text printed on white paper, and figures reproduced in tones of gray. There is no use of colour in the book, other than on the cover. A Web-based enhanced version of this publication could include a myriad of features associated with websites, such as:

- Illustrations, figures, and tables in colour;

- Internal hyperlinks between sections of the book;

- External hyperlinks to related Internet-based materials;

- Supplementary resources for book chapters (e.g., recent publications, multimedia, and other materials).

Many additional features are also possible:

- Interlinking index terms with book text;

- Chapter references with hyperlinks;

- Author search via Google Scholar for other publications;

- Keyword search for similar publications;

- Periodic updating of material by chapter authors;

- Comment and blog functions facilitating interactions between readers and authors.

The publisher granted permission to place the text of the book on the website, and this allowed us to illustrate how the chapters would be presented in both PDF and html file formats. At this time, two chapters have been prepared in this fashion. Figure 10 shows the website page with links to presentations given by authors. Figure 11 illustrates information on related books and links to sites associated with these publications. Figure 12 depicts author information from the database created for the book.

Although preparation of the website complementing this book is well underway, the text for all 17 chapters has not yet been uploaded to the site. Once completed, these chapter presentations will also include the following functionalities:

- Search function through chapter texts;

- Hyperlinks embedded in chapters;

- Pop-up figures and tables in chapters.

\section{Scholarly and Research}

Communication

VOLUME 4 / ISSUE 1 / 2013 


\section{Scholarly and Research}

\section{Communication}

VOLUME 4 / ISSUE 1 / 2013

\section{e-Research: Transformation in Scholarly Practice}

An anhanced puhlicatian axampanylng tha traditianally puhlishes baak (Routiodga, 20no)

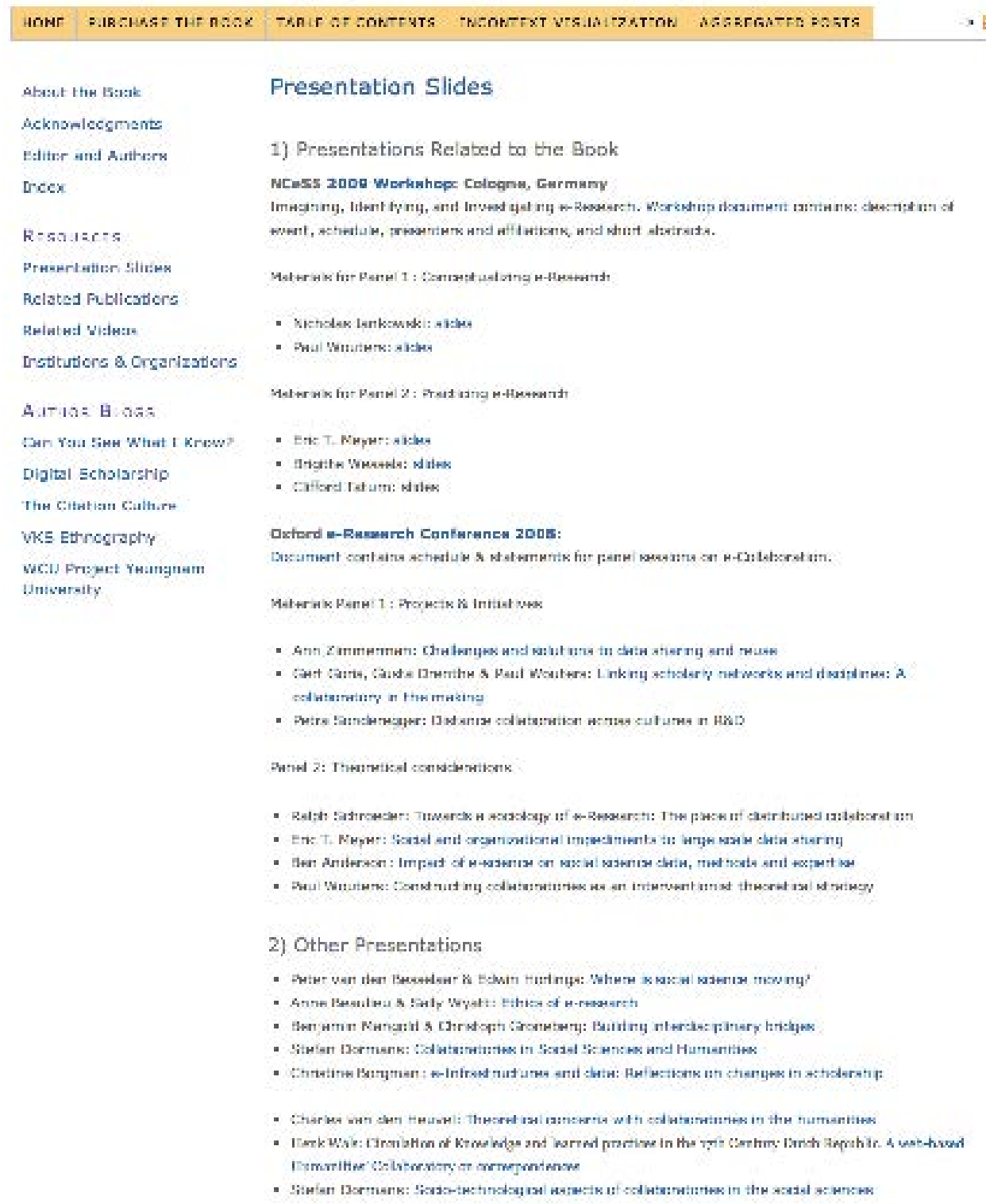

Figure 10: Links to presentations, $e$-Research Website 
e-Research: Transformation in Scholarly Practice

An anhancod publicatian axampanying the traditianally puhlishod baak (Routiadge, 20n9)

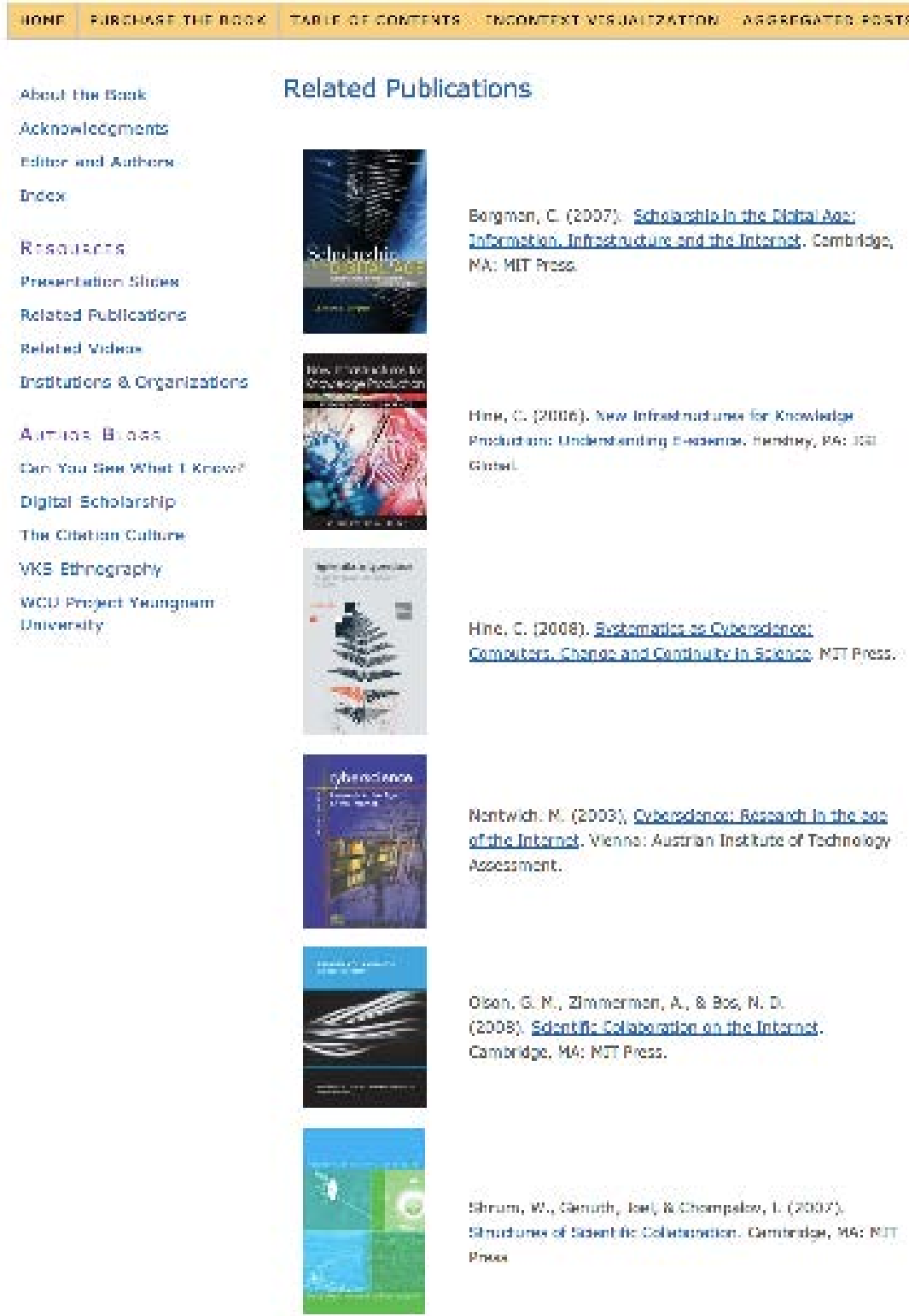

Scholarly and Research

Communication

VOLUME 4 / ISSUE $1 / 2013$

Figure 11: Publications related to e-Research book 


\section{Scholarly and Research}

\section{Communication}

VOLUME 4 / ISSUE 1 / 2013

\section{e-Research: Transformation in Scholarly Practice}

An enhanced pubilcation accompanying the traditionally pubilahod bock (Routledge, 2009)

\section{InContext Visualization}

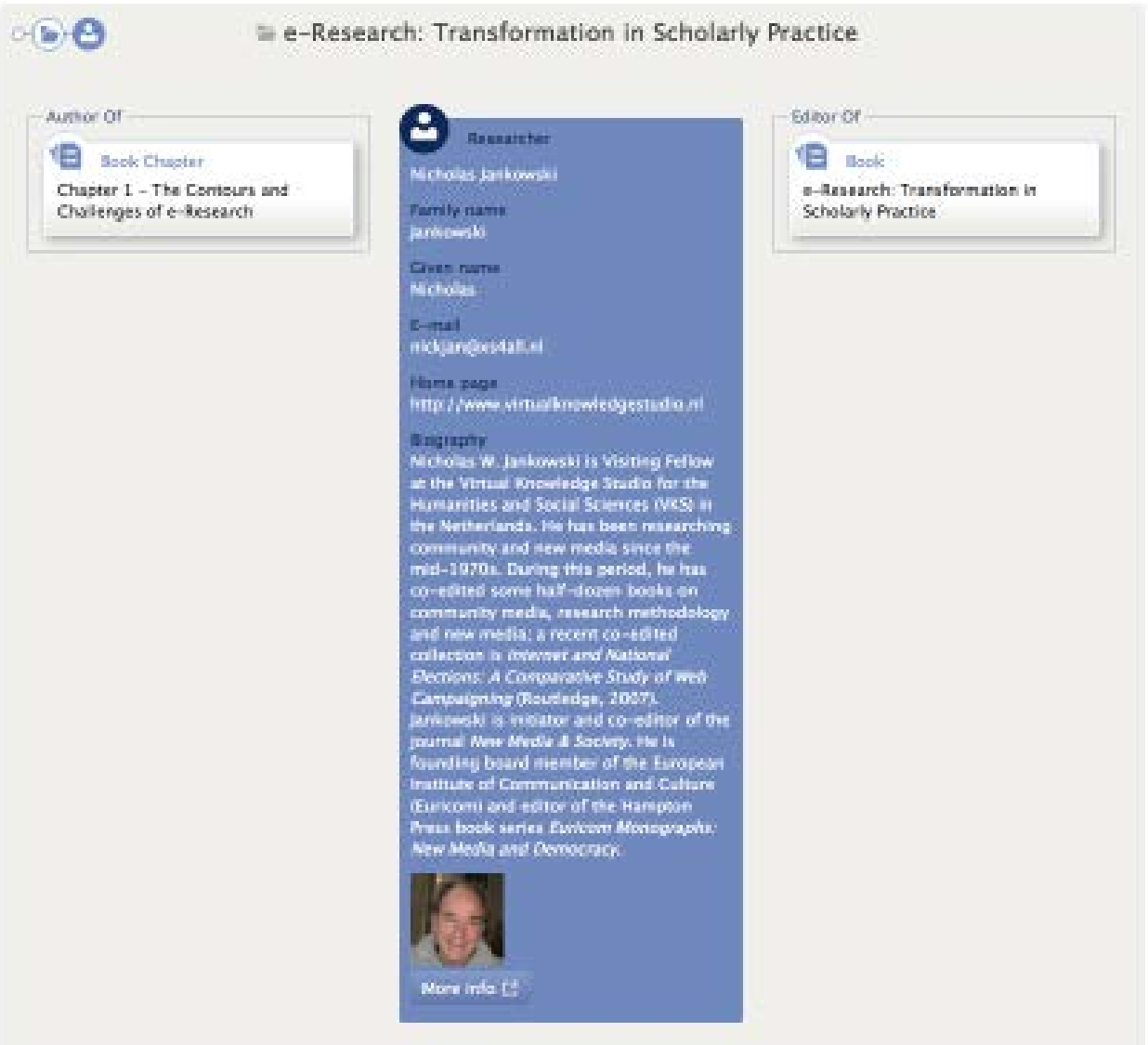

Figure 12: Author information, $e$-Research author database

\section{BOOK 2: VIRTUAL KNOWLEDGE}

The book manuscript Virtual Knowledge is based on research prepared by scholars associated with the Virtual Knowledge Studio (VKS) for the Humanities and Social Sciences, established by the Royal Netherlands Academy of Arts and Sciences (KNAW) in 2006. The primary objective of the $\mathrm{VKS}^{18}$ was to facilitate innovative research practices in the humanities and social sciences, and the book Virtual Knowledge is designed to reflect that aim. Contributions came from scholars associated with the three divisions of the VKS: in Amsterdam, Rotterdam (Erasmus Studio), and Maastricht (Maastricht Studio). One function of the book project was to enhance cohesion among the wide array of VKS projects and to foster interactions among staff at the three divisions of VKS.

From its conception, VKS intended to initiate and conduct new research practices and to engage with ongoing innovative practices of other researchers. In this regard, VKS researchers were both "makers" and "observers" of new digital scholarship. Two notions central to Science and Technology Studies (STS), which constituted the home discipline of many of the central members of the VKS, are practice and 
community. These notions are reflected in the preparation of Virtual Knowledge and in the complementing website. Regarding the book, three workshops were conducted during preparation of chapters; regarding the website, one workshop was held related to preparing and uploading contact for the site.

Based on interactions during preparation of the book, it was decided to prepare a Web complement to the print volume. Several considerations contributed to adoption of this idea to:

- Continue interactions among authors;

- Support the formation of a community around ideas expressed in the book;

- Embed the book in an emerging environment of similar books;

- Disseminate and promote the book.

To support preparation of an enhanced publication for the book and to explore how preparation of such a Web complement might facilitate the previously mentioned community function, a workshop was organized in April 2011 for book contributors. Of the 17 contributors, seven attended the workshop. The event provided the opportunity for participants to become familiar with the website and the general procedures for uploading information, including bibliographic entries that were submitted with a specially prepared plugin for the WordPress site. The workshop concluded with a general discussion, during which some persons expressed regret at not being involved in an earlier stage of the process, in order to contribute to the design process and the user interface with the site. This discussion was continued in a post-workshop survey that allowed all contributors to reflect on the website under construction.

The level of contribution during and after the workshop was modest. While content has been uploaded to the site, much remains to be completed. That acknowledged, preparation for the workshop did stimulate members of the project team to complete the website template and specially developed plugins for bibliographic entries. Some of the criticisms of the workshop and reservations about an enhanced publication included:

- Inadequate involvement of the book editors in the planning;

- Unclear value of a book website for authors;

- Time constraints preventing engagement at the desired level;

- Uncertainty about the utility of some site features, including author photos and videos;

- Technical problems experienced with the site, including functioning of the interface;

- Insufficient support from project team members in using the site.

Some of the positive reactions to the workshop and Enhanced Publication Project included:
VOLUME 4 / ISSUE 1 / 2013 


\section{Scholarly and Research}

\section{Communication}

VOLUME 4 / ISSUE 1 / 2013
- Appreciation for being able to link references;

- Acknowledgment of potential value in creating cohesion of edited collections through an enhanced publication;

- Value of website for author visibility;

- Relevancy of site to own research practices.

Negotiations are ongoing with MIT Press, the publisher of the book, for development of an enhanced version. Preliminary reactions reflect interest in publishing the volume and in combining the book with an enhanced publication in the form developed during this project. To this end, a website - under construction and not yet publically accessible - has been prepared and includes the basic functionalities included in the WordPress template.

Many of the functionalities for the accompanying website will remain important and further work will be required to complete preparation of the content related to these features (e.g., providing supplementary resources such as links, uploading bibliographic entries, and completing video films of authors reflecting on their chapters).

It is anticipated that a second workshop for authors may be necessary once arrangements have been made with the publisher regarding preparation of the book. This workshop will build on the experiences of the initial workshop held during this project.

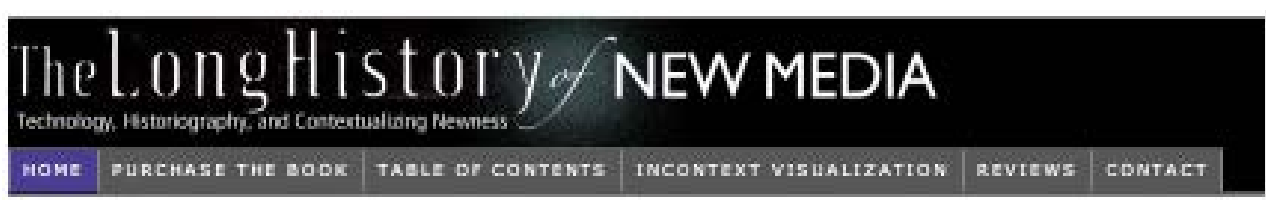

\section{Enhanced Publication Web Site for LHNM}

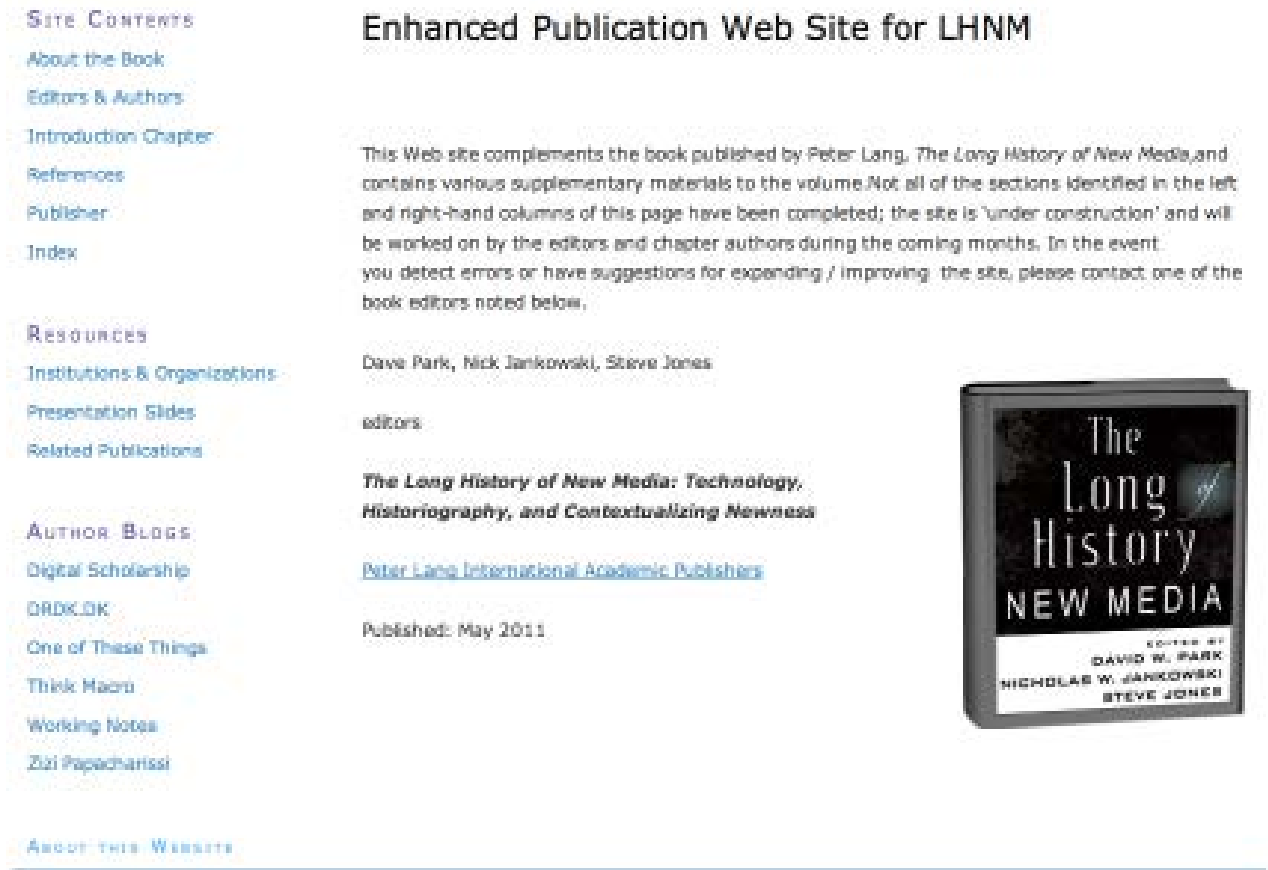

Figure 13: Homepage, Long History of New Media 
Book 3: LONG History OF NEW Media

The third book that is part of this project was released by Peter Lang in May 2011 and is entitled The Long History of New Media: Technology, Historiography, and Contextualizing Newness. As with the other books in the project, this is an edited volume and has been prepared and published in a manner reflective of conventional procedures for scholarly publishing. The book was released as a paperback and the cover consists of a designed arrangement of book title and names of editors. The text of the book is printed in black ink on white paper; there are few illustrations and no tables in the book.

The website constructed for The Long History of New Media contains a similar set of features as prepared for the other two books and uses the same WordPress template for the site; see Figure 13 illustrating the homepage of the site and Figure 14 containing biographical sketches of contributing authors.

Inasmuch as the book was recently released by the publisher Peter Lang, and no prior arrangement had been made for reproducing the full book manuscript, only introductory paragraphs from the chapters have been uploaded to the site, along with the text of the introduction chapter.

\section{Book 4: Digital Media and Society}

The website for this book is under construction and the content will mirror the content available on the $e$-Research book website and include the following features:

- Book-related materials: description of book, table of contents, chapter abstracts, figures from chapters, compilation of references, and publisher information;

- Profiles of contributors: photos and bios of authors and editors;

- Supplementary resources: lists of institutions, publications, videos, and presentations related to Web history;

- Topic-related blogs: group blog for authors of the book, individual blogs by book authors, and other blogs relevant to the themes in the book;

- Interlinking index terms with book text;

- Figures reproduced on website; figures in colour;

- Chapter references with hyperlinks and an overall bibliography for book;

- Author search via Google Scholar for other publications by author;

- Keyword search for similar publications based on chapter titles.
VOLUME 4 / ISSUE $1 / 2013$ 
Scholarly and Research

Communication

VOLUME 4 / ISSUE 1 / 2013

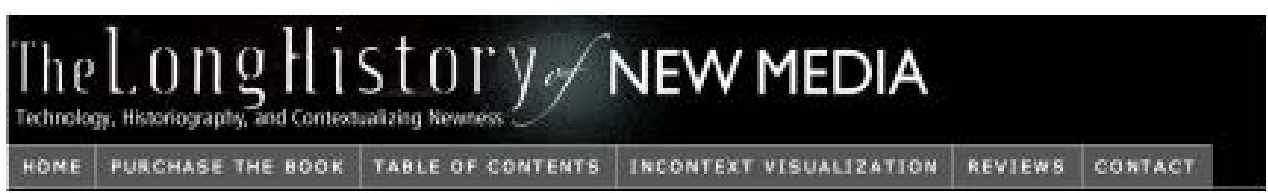

Barbara Adkins

About the Bool

Editors a Aubset:

teredodenen Chapter

Reserentes

Retsher

Indas

Resources

Inakitutoes \& Organiastoms

Presantation Sides

Resanas puctrations

Authok BLoes

Digtal sotolansip

Deok, DK

Dre of These Things

Think Macro

Working Notes

Ziv Papacheres

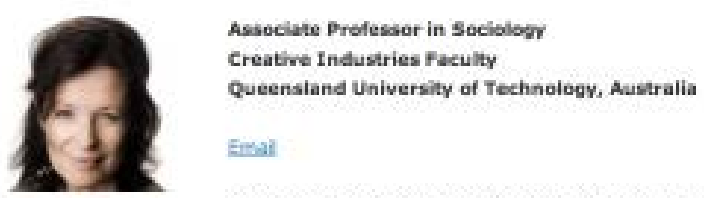

Bartara Adkins is Aesociate Prokssor in Seckebgr in the Crative Industries

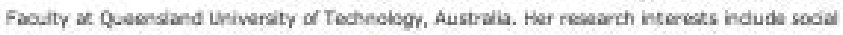
theary and the philosophy of inquiry with recent focus on the notion of "partiopstion" and its relotionshio to digtal todinologes at the leved of the micro-processes of everydgy use of digkel tools. and the broode dprismics of social feids. Papes in this area have been publathed in journsis such $m$ Ausbralion bownal of Communication, Information, Communcation and Soclety, and Qualtative

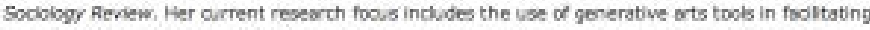
perticlootion in the hed of curure, ond the role of digkal technologles akh respect to the interests of the sutjects of natiana public apologies such as the recent apology to the "Fongotten Nustralons:-

Figure 14: Author biographical sketches, Long History of New Media

\section{Conclusion}

This project involved the development of hybrid Web venues for three traditionally published scholarly books. These Web venues extended beyond the increasingly common practice of preparing electronic brochure-style websites accompanying scholarly titles; the sites developed within this project incorporate features that reflect what has come to be termed enhanced publishing. While there is a broad range of interpretation as to what constitutes an enhanced publication, the features included in the websites of the Enhanced Scholarly Publication project reflect an interlinking of components of the publications in a manner made possible by utilizing Web 2.0 applications and practices, and content structures facilitated by Semantic Web formats. This involved construction of a database for each of the book titles, allowing for aggregation of content within and across the individual book websites.

The initial WordPress template for the book websites was redesigned to facilitate ease of use by book authors and to ensure basic uniformity in the presentation of site content. Plugins for the site were designed, tested, and implemented; these plugins facilitate author bios and reference management with a variety of display options within each book chapter and for the book as a whole. Websites were prepared for each of the four books using the common template, and illustrations of content for each of the books was uploaded to the respective sites. The amount of content uploaded varies per book because of the different phases of completion and the particular "life cycles" of each book. For example, the book e-Research was released two years ago and 
the publisher agreed to allow the full text of the book to be placed on the website. A database has been constructed for each of the three book titles and these individual databases are integrated into an overall database.

Looking back on the project, the undertaking involved an accelerated learning experience in the terminology and models underlying the notion of enhanced publishing as formulated by the funding organization, the SURFfoundation. While the websites for the books are not equally developed and completed, each reflects a different phase of the book life cycle and all are based on preparation of an overarching database containing materials from those monographs.

One of the most interesting outcomes of this project was the implementation of the InContext visualizer to this set of books. As the navigation interface for users, it introduced the Semantic Web technology to the non-specialist users and illustrates the kinds of information that is exposed for machine readability.

To evaluate this project properly, it is important to realize that enhanced publications are still in a preliminary phase of development. Adopting a phrase from innovation studies, it can be said that the development is experiencing a "precambrian explosion" of many different approaches, small in scale, coexisting, and often short in lifespan (Kauffman, 1995, p. 281). The development of dominant technologies and design has yet to be achieved. This concerns not only enhanced publications but also Semantic Web technologies as is evident in Google's Knowledge Graph ${ }^{19}$ or Wolfram's Computational Knowledge Engine, ${ }^{20}$ both of which are considered alternatives to a "Web of data."

In conclusion it should be stressed that the Enhancing Scholarly Publications project was practically oriented and exploratory; it did not have theoretical aspirations or intend to perform empirically-grounded research. The exploration did reveal, however, the need to extend the theoretical understanding of the transformations that scholarly publishing is undergoing, and to develop an empirical research agenda related to those understandings. Although separate from this project, some of the team members have been undertaking theoretical and empirical research related to the concept of openness and scholarly communication, which could guide further practically-oriented projects at enhancing publications (Tatum \& Jankowski, 2012). The research agenda that might evolve from this exploration could include formative case studies of similar initiatives to enhance scholarship, thereby contributing to both theory construction and scholarly practice.

\section{Acknowledgements}

The authors gratefully acknowledge the financial and collegial support provided by the SURFfoundation and the e-Humanities Group. This report is a revised version of the paper prepared for the PKP conference 2011, available at: http://pkp.sfu.ca/ocs/pkp/ index.php /pkp2011/pkp2011/paper/view/326/185. The website for the project Enhancing Scholarly Publishing provides additional materials on which this paper is based: http:// digital-scholarship.ehumanities.nl/enhanced-publications. A video describing this and other SURF enhanced publications projects is available at: http://www.surffoundation.nl/ en/themas/ openonderzoek/verrijktepublicaties/Pages/default.aspx.
VOLUME 4 / ISSUE 1 / 2013 
Scholarly and Research

\section{Communication}

VOLUME 4 / ISSUE 1 / 2013

\section{Notes}

1. This report presents a specific project "Enhancing Scholarly publications in the Humanities and Social Sciences," presented at the PKP Scholarly Publishing Conference, September 26-28, 2011, Berlin, Germany, http://pkp.sfu.ca/ocs/pkp/ index.php/pkp2011/pkp2011 .

2. See, e.g., the NSF Data Sharing Policy, available at: http://www.nsf.gov/bfa/dias/ policy/dmp.jsp .

3. See SURF website for details: http://www.surffoundation.nl/en/themas/ openonderzoek/ verrijktepublicaties/Pages/default.aspx .

4. The project has been presented by a film produced by SURF: http://www.youtube .com/watch? $\mathrm{v}=\mathrm{NhkD} 2 \mathrm{OQSLNw} \&$ feature $=\mathrm{relmfu}$. Another film introduces all six projects: http://www.youtube.com/watch?v=FHI4J94YUUk\&feature=youtu.be .

5. One example is the website announced in July 2011 as supplement for the Harry Potter series (http://www.pottermore.com/). More elaborate, however, is the specially designed app for the iPad version of Al Gore's Our Choice (Gore, 2009), released by Push Pop Press in 2011. The website accompanying the book, http:// ourchoicethebook.com/site_media/ index2.html, reflects many of the features found on websites complementing published books: illustrations, sample texts, order information, references.

6. The iPad app for The Iliad was developed by the Center for Visualization and Virtual Environments at the University of Kentucky; see http://viscenter.wordpress .com .

7. An extensive overview of the additional iPad features available on the app of On the Road can be seen at the Penguin Books website for the Amplified Edition: http:// us.penguingroup.com/static/pages/features/amplified_editions/on_the_road.html .

8. Publisher Farber and Farber prepared a special website for the release of this iPad app: http://thewastelandforipad.com .

9. At the time of this writing, early 2012, Touch Press has released five titles for iPad; see the publisher website for details: http://www.touchpress.com .

10. http://ocw.mit.edu/ans7870/21f/21f.o27/home/index.html

11. See Elsevier press release for details: http://www.elsevier.com/wps/find/authored _newsitem.cws_home/companynewso5_01279.

12. The EU-funded project DRIVER (Digital repository Infrastructure Vision for European Research) was responsible for this and other reports; see project website for an overview of studies: http://www.driver-repository.eu .

13. http://www.openarchives.org

Nicholas W. Jankowski, Andrea Scharnhorst, Clifford Tatum, \& Zuotian Tatum. (2012). Enhancing Scholarly Publications: Developing Hybrid Monographs in the Humanities and Social Sciences. Scholarly and Research Communication, 4(1): 010138, 26 pp. 
14. http://w3techs.com/technologies/overview/content_management/all

15. http://ep-books.ehumanities.nl/semantic-words

16. For background and rationale of this hybrid approach to enhanced publications, see the project final report (Jankowski, Scharnhorst, Tatum, \& Tatum, 2011), available on the Digital Scholarship website: http://digital-scholarship.ehumanities.nl/ enhanced-publications .

17. The WordPress community has produced more than 15,000 plugins; see http:// wordpress.org/extend/plugins .

18. The VKS concluded operation on 31 December 2010 and the e-Humanities Group was created to continue and extend activities of the VKS under a modified organizational structure. This transition is discussed further on the e-Humanities Group website: http:// ehumanities.nl .

19. http://googleblog.blogspot.nl/2012/05/introducing-knowledge-graph-things-not html

2o. http://www.wolframalpha.com

\section{Websites}

Co-Authors Plus: http://wordpress.org/extend/plugins/co-authors-plus

Ninja Page Categories and Tags: http://wpninjas.net/plugins/ninja-page-categories-and-tags/

User Avatar: http://wordpress.org/extend/plugins/user-avatar

Enhanced Bibliplug: http://ep-books.ehumanities.nl/semantic-words/enhanced-bibliplug

Enhanced Publication for WordPress: http://ep-books.ehumanities.nl/semantic-words/enhancedpublication-plugin-for-wordpress

InContext Visualiser: http://www.surffoundation.nl/en/projecten/Pages/

EscapeVisualisationcomponent.aspx

Semantic WORDS: http://ep-books.ehumanities.nl/semantic-words

WordPress: http://wordpress.org

Zotero: http://www.zotero.org

\section{References}

Boulal, Anouar, Lordanidis, Martin, Quast, Andres, \& Schirrwagen, Jochen. (2010). Report on enhancing interoperability between existing open access publication infrastructures. Cologne, Germany: Bielefeld University Library. URL: http://www.eco4r.org/downloads/eco4r_report_ compoundobjects_draft.pdf [January 9, 2012].

Berners-Lee, Tim, Hendler, James, \& Lassila, Ora. (2002). The Semantic Web - A new form of Web content that is meaningful to computers will unleash a revolution of new possibilities. Scientific American, Special online issue, 24-30. URL: http://csis.pace.edu/ marchese/CS835/Lec9/112_ SemWeb.pdf [June 12, 2012].

Nicholas W. Jankowski, Andrea Scharnhorst, Clifford Tatum, \& Zuotian Tatum. (2012). Enhancing Scholarly Publications: Developing Hybrid Monographs in the Humanities and Social Sciences. Scholarly and Research Communication, 4(1): 010138, 26 pp.
Scholarly and Research

VOLUme 4 / ISSUE 1 / 2013 


\section{Scholarly and Research} Communication

VOLUME 4 / ISSUE 1 / 2013
Breure, Leen, Voorbij, Hans, \& Hoogerwerf, Maarten. (2011). Rich Internet publications: 'Show what you tell.' Journal of Digital Information 12(1). URL: http://journals.tdl.org/jodi/article/ view/1606/1738 [January 9, 2012].

Chown, Marcus. (2011). Solar system for iPad. London, UK: Touch Press. URL: http://itunes.apple .com/us/app/solar-system-for-ipad/id406795422?mt=8\&ign-mpt=uo\%3 D4 [January 9, 2012].

Gore, Al. (2009). Our choice: A plan to solve the climate crisis. New York, NY: Rodale Books. URL: http://ourchoicethebook.com/site_media/index2.html [January 9, 2012].

Hoogerwerf, Maarten, Jong, Jan de, \& Scholte, Hans. (2009). Enhanced publications in archaeology: An analysis of potential enhancements. URL: https://www.surfgroepen.nl/sites/JALCproject/ Project\%2oresults/WP2\%20-\%2oEnhanced\%2oPublications\%20in\%2oArchaeology.\%20An\%20 analysis\%20of\%2opotential\%2oenhancements.pdf [January 9, 2012].

Jankowski, Nicholas W. (Ed.) (2009). E-Research: Transformation in scholarly practice. New York, NY: Routledge.

Jankowski, Nicholas W. (2011). Enhancing scholarly publishing in the humanities and social sciences: Innovation through hybrid forms of publication. [Project proposal]. URL: http://digitalscholarship.ehumanities.nl/enhanced-publications/ [January 9, 2012].

Jankowski, Nicholas. W. (forthcoming). Digital media: Concepts \& issues, research, \& resources. Cambridge, UK: Polity Press.

Jankowski, Nicholas W., Scharnhorst, Andrea, Tatum, Clifford, \& Tatum, Zuotian. (2011). Enhancing scholarly publishing in the humanities and social sciences: Innovation through hybrid forms of publication. [Project report]. URL: http://digital-scholarship.ehumanities.nl/enhancedpublications/ [January 9, 2012].

Kauffman, Stuart A. (1995). At home in the universe. The search for laws of self-organization and complexity. Oxford, UK: Oxford University Press.

Mark Twain Project. (2012). Home. URL: http://www.marktwainproject.org/ [June 22, 2012].

Meroño-Peñuela, Albert, Ashkpour, Ashkan, Van Erp, Marieke, Mandemakers, Kees, Breure, Leen, Scharnhorst, Andrea, Schlobach, Stefan, \& Van Harmelen, Frank. (2012). Semantic technologies for historical research: A survey. Semantic Web - Interoperability, Usability, Applicability. URL: http://www.semantic-web-journal.net/content/semantic-technologies-historical-researchsurvey [September 24, 2012].

Palmer, Rodney, \& Frangenberg, Thomas. (Eds.) (2003). The Rise of the Image: Essays on the History of the Illustrated Art Book (Reinterpreting classicism). Surrey, UK: Ashgate Publishing.

Park, D., Jankowski, N.W., \& Jones, S. (2011). The Long History of New Media: Technology, Historiography, and Newness Contextualized. New York, NY: Peter Lang.

SURFfoundation. (2010). Wat is een Verrijkte Publicatie? [What is an Enhanced Publication?] URL: http://www.surffoundation.nl/nl/themas/openonderzoek/ verrijktepublicaties/Pages/default. aspx [January 9, 2012].

Tatum, Clifford, \& Jankowski, Nicholas. (2012). Beyond open access. A framework for openness in scholarly communication. In: Paul Wouters, Anne Beaulieu, Andrea Scharnhorst \& Sally Wyatt (Eds.), Virtual Knowledge: Experimenting in the Humanities and Social Sciences. (pp. 183-218). Cambridge, MA: MIT Press.

Wikipedia. (2012). Semantic web. URL: http://en.wikipedia.org/wiki/Semantic_Web [June 22, 2012]. Wouters, P., Beaulieu, A., Scharnhorst, A., \& Wyatt, S. (2012). Virtual Knowledge: Experimenting in the Humanities and Social Sciences.. Cambridge, MA: MIT Press.

Woutersen-Windhouwer, Saskia \& Brandsma, Renze. (2009). Report on Enhanced Publications; State-of-the-Art. Project DRIVER (Digital Repository Infrastructure Vision for European Research II). URL: http://dare.uva.nl/document/173780 [January 9, 2012]. 